\title{
Memoria, utopía y liberación: las condiciones de lo posible desde la filosofía de la liberación de Franz Hinkelammert
}

Memory, utopia and Liberation: the conditions of the possible from the philosophy of liberation of Franz Hinkelammert

Memória, utopia e libertação; as condições do possível a partir da filosofia da libertação de Franz Hinkelammert

Fecha de entrega: 10 de diciembre de 2013 Fecha de evaluación: 10 de febrero de 2014 Fecha de aprobación: 16 de marzo de 2014

Arturo Orrego-Echeverría*

\section{Resumen}

El presente texto reflexiona sobre la noción de utopía expuesta en la filosofía de la liberación de Franz Hinkelammert. Se exponen las condiciones de posibilidad de la misma y se entiende como totalidad ausente, lo que no hace que no se pueda cumplir, pues es entonces cuando se podrían generar toda suerte de violencias y totalitarismos. En ese sentido, la noción de utopía se convierte en eje fundamental para la transformación de la sociedad. En contraposición a esta

Filósofo y magister en Filosofía de la Universidad Santo Tomás, ha sido profesor en la Universidad Minuto de Dios y la Incca de Colombia. Ha publicado artículos sobre la sacralidad de la tierra, así como sobre responsabilidades éticas antes los derechos humanos. Correo electrónico: Arturo.orrego@gmail.com 
aproximación, se describe la manera como la modernidad y la posmodernidad Occidentales han generado un antiutopismo que encubre la posibilidad de otros mundos posibles, lo que no es otra cosa sino la imposición de una única utopía a la luz de la cual todas las otras alternativas utópicas son irracionales e ilusorias.

Palabras clave: utopía, totalidad ausente, totalidad presente, memoria, liberación.

\section{Abstract}

This text considers the notion of utopia in the philosophy of liberation of Franz Hinkelammert. By highlighting the conditions of possibility for the notion of utopia through thinking of it as an "Absent-totality," this consideration does not allow utopia to actualize itself because this leads to myriad forms of violence and totalitarianism. To that end, the notion of utopia becomes the axis fundamental to societal transformation. This consideration in located in opposition to how Western modernity and postmodernity have generated an antiutopianism, that which conceals the possibility of "other possible worlds," and imposing of a single utopian light under which all other utopias are irrational and illusory.

Keywords: utopía, absent totality, present totality, memory, liberation. 


\section{Resumo}

O presente texto reflete sobre a noção de utopia exposta na filosofia da libertação de Franz Hinkelammert. Expõem-se as condições de possibilidade da mesma e é compreendida como totalidade ausente, o que não faz que não se possa cumprir, pois é então quando puderse-ia gerar toda classe de violências e totalitarismo. Nesse sentido, a noção de utopia torna-se a pedra fundamental para a transformação da sociedade. Em contraste com esta abordagem, descreve-se a maneira como a modernidade e a pós-modernidade Ocidentais tem gerado um anti-utopismo que encobre a possibilidade de outros mundos possíveis, o que não é nada mais do que a imposição de uma única utopia, à luz da qual todas as demais alternativas utópicas são irracionais e ilusórias.

Palavras-chave: utopia, totalidade ausente, totalidade presente, memória, liberação. 


\section{Filosofía y teología de la liberación y su relación con la historia y la memoria}

La teología significa aquí la consciencia de que el mundo es un fenómeno, de que no es la verdad absoluta ni lo último. La teología es [...] la esperanza que la injusticia que caracteriza el mundo no puede permanecer así, que lo injusto no puede considerarse como la última palabra.

HORKHEIMER

La memoria histórica, especialmente la colectiva, implica no solo asumir al pasado como un momento ya vivido, sino como condición del presente y, en ese sentido, como posibilidad de futuro, tal como lo señala Pedreño (2004) cuando afirma que:

Para que evoque realmente lo que es la memoria histórica, deberíamos matizarla añadiendo que 'el pueblo que no conoce su historia no comprende su presente y, por lo tanto, no lo domina, por lo que son otros los que lo hacen por él'. Ese dominio se manifiesta en lo ideológico-cultural, en lo económico y en lo político. El desconocimiento provoca falta de comprensión sobre los procesos históricos que han dado como resultado nuestro presente [...]. (p. 2)

Esto quiere decir que pensar en la constitución de una memoria histórica contiene en sí la proyección utópica de un futuro que se encuentra abierto como la existencia misma del sujeto - en sentido del Dasein heideggeriano-. Vista desde esta perspectiva, la memoria histórica se nos presenta como elemento indispensable para repensar el presente y la existencia misma de los sujetos que lo piensan, lo que supone una tensión, una cierta dialéctica del tiempo, pero de cara a la apertura de un futuro que ha de ser asumido por los sujetos protagonistas de la historia: "[n]o somos, realmente, dueños de nuestro presente, porque solo conocemos nuestro pasado vagamente" (Pedreño, 2004, p. 2).

Ahora bien, los sujetos que construyen, narran y simbolizan la memoria histórica, en cuanto históricos, son justamente aquellos a los que se ha excluido en la historia. No es esta entonces la memoria de los vencedores, quienes tradicionalmente han sido los subiectum enunciationis, quienes comúnmente han narrado la historia (Orwell, 2009; Leventhal, 2012), sino la de los “vencidos”, aquellos negados y subalternizados, 
cuyas maneras de existir, resistir y de nombrar la historia, es decir, dar sentido a la existencia, no han sido tomadas en cuenta en los anales de la historia oficial.

Justamente una de las reflexiones, tanto filosófica como teológica, que emerge de las narrativas, mejor, de los gritos de aquellos que han sido borrados como sujetos históricos es la denominada filosofía y teología de la liberación latinoamericana. Estas, al partir no solo del reconocimiento de la historia como escenario de la manifestación del dios de la vida y, en consecuencia, de la realidad misma, hacen emerger el "grito del sujeto" que ha sido subyugado por la misma institucionalización de la historia, poniendo la ley y no la legitimidad como criterio de racionalidad. En este sentido, se reconoce en el nacimiento de la teología y filosofía de la liberación un vínculo estrecho con la historia, en la medida en que esta se constituye como un escenario para la manifestación de la realidad de Dios en la humanidad. En efecto, esta no es asumida meramente como la suma de las experiencias de los sujetos en el marco de un determinado espacio y tiempo, sino como la condición misma de posibilidad de la existencia; de ahí que, como bien lo afirma Gutiérrez (1975), "[1]a historia humana es, ante todo, abertura, al futuro" (p. 32).

Esta interpretación de la historia toma distancia de los abordajes historicistas clásicos que, como bien advierte Foucault, no son otra cosa, sino una de las manifestación del poder como elemento modelador de las subjetividades, como historia de los vencedores: "[1]a objetividad en el historiador es la inversión de las relaciones de querer en saber, y es, al mismo tiempo, la creencia en la Providencia, en las causas finales, y en la teleología” (1992, p. 18).

En este sentido de la historia como apertura al futuro es que la memoria del pasado recobra importancia, pero también la noción misma de futuro, pues se constituye como una tarea, un proyecto. Es decir, este se constituye, a la luz de la memoria histórica, no como un arqueológica histórica, sino como un quehacer político y emancipatorio.

En este sentido de la historia es que el filósofo y teólogo peruano Gustavo Gutiérrez afirma que esta "[...] aparece como una tarea, como un quehacer político, construyéndola el hombre se orienta y se abre al don que da sentido último a la historia" (1975, p. 32). Si esta es la condición de la historia, la tarea de la teología, por lo menos de la de la liberación — podríamos decir, también la de la filosofía de la liberación-, es reflexionar críticamente sobre la praxis histórica, pues esto es lo que la convierte 
en una teología liberadora, en la medida en que su manera de leer la historia no le permite legitimar el presente. En palabras del intelectual peruano:

Una teología que no se limita a pensar el mundo, sino que busca situarse como un momento del proceso a través del cual el mundo es transformado: abriéndose - en la protesta ante la indignidad humana pisoteada, en la lucha contra el despojo de la inmensa mayoría de lo hombres, en el amor que libera, en la construcción de una nueva sociedad, justa y fraternal— al don del Reino de Dios. (Gutiérrez, 1992, p. 41)

Lo anterior encierra un cierto sentido de lo utópico, que está dado en un horizonte de radicalización de la historia, en el horizonte de posibilidad de los sujetos concretos que participan en la historia.

Al respecto, el filósofo, teólogo y economista Franz Hinkelammert ha desarrollado una amplia reflexión sobre las implicaciones que tiene la fe cristiana en el marco de la historia, al concebirse como una proyección utópica de liberación de los sujetos. El intelectual plantea, en su obra Crítica a la razón utópica (1990), lo que ha denominado la "factibilidad trascendental", en el marco de una crítica al pensamiento neoliberal, como proyecto utópico (es decir, como posibilidad última de la realidad humana) y, en ese sentido, como la muerte de las otras utopías (de la posibilidad de agenciamientos de otros mundos posibles), funcionando a su vez como pensamiento antiutópico.

\section{Fin del socialismo soviético como utopía e imposibilidad de la filosofía y teología de la liberación}

Comprendemos la filosofía y teología de la liberación como dos proyectos históricos de construcción del saber que emergen en América Latina, acompañados de múltiples procesos sociales de transformación. Si bien las expresiones filosofía y teología latinoamericana abarcan no solo la perspectiva que se ha adjetivado como liberacionista, esta última se ha dado no solo en el seno de la academia latinoamericana, sino en la experiencia de los pueblos empobrecidos. En otras palabras, la opción para lo marginados en estos abordajes es un eje epistémico desde el cual se lee el contexto social, político y filosófico. Es, por esto, que los abordajes latinoamericanos y, particularmente, los de cuño liberacionista son los que mejor pueden dar cuenta de la 
memoria histórica de los pueblos que no han tenido historia y que están en pugna de liberación.

Ahora bien, en las últimas décadas del siglo XX, los abordajes, métodos, posturas y utopías de los enfoques liberacionistas han sido puestos en cuestión, principalmente desde dos flancos interdependientes: el primero de estos está representado por una crítica que emerge desde ciertas lecturas de América Latina y su relación con la Modernidad y con la colonialidad, leída esta desde la positividad de los abordajes posmodernos, de los aportes del francés Michel Foucault - y sus discípulos- y los hoy conocidos estudios culturales latinoamericanos que anuncian a viva voz la imposibilidad de un pensamiento propiamente latinoamericano, de una identidad latinoamericana.

Según Santiago Castro-Gómez, representante en Colombia de esta corriente de pensamiento, la posmodernidad no es, como afirman los filósofos y teólogos de la liberación, una nueva versión del neoliberalismo, su ideologización llevada al extremo - Modernidad al extremo-, sino una realidad dada en el mundo de la vida, producto del desencantamiento de la Modernidad. Para el autor colombiano, las críticas a la lectura de la posmodernidad de cuño liberacionista "se basan en 'clichés' popularizados por filósofos aferrados al viejo ideal nostálgico de la 'identidad latinoamericana', que miran estupefactos un pensamiento tan radicalmente diferente al suyo" (Castro-Gómez, 2011, p. 31).

Continúa el colombiano afirmando, desde una lectura apasionada de cuño foucaultiano, que justamente el lugar que se le da a los pobres en la teología y filosofía de la liberación, en cuanto sujetos trascendentales, es producto de una mala interpretación y confusión del "afuera" con lo "otro":

[...] precisamente esta confusión del 'afuera' con el 'otro' es lo que lleva a Dussel a contraponer maniqueamente un 'poder bueno' y un 'poder malo', 'aquel proveniente 'de abajo', del mundo de los pobres, y este proveniente de 'arriba', de los intereses egoístas del imperialismo. Contraposición en extremo problemática porque el poder, como bien lo mostró Foucault, no es un atributo vinculado al Estado colonial o a una clase social o a un determinado 'modo de producción', sino una relación de fuerzas que atraviesa tanto a dominantes como a dominadores. (2011, p. 39) 
Olvida el filósofo posmoderno, quizá debido a la ausencia de una interpretación de la realidad económica actual, que estas relaciones de poder, en las que tanto el dominante como el dominado se circunscriben, hacen de los sujetos dominados los no sujetos. Es decir, en la lógica en la que bien Foucault circunscribe el "funcionamiento" del poder, se pierde de vista justamente aquello que la tradición liberacionista busca restaurar, a saber, la condición de in-humanidad a la que están sometidos aquellos "dominados" inmersos en la "neutral" red del poder. Mientras que los dominadores, al igual que los dominados, están inmersos en la relación de fuerzas del poder — por llamarle de alguna manera-, son estos sujetos, clases, modos de producción, Estados los que disfrutan del lugar privilegiado que la relación de fuerzas del poder les ha dado, mientras los otros miles han sido condenados a la no humanidad.

En este sentido, desde la perspectiva de teóricos como Castro-Gómez, la razón latinoamericana ha caído en la reproducción de las matrices coloniales que permean incluso a la noción de utopía que subyace a las reflexiones liberacionistas así como a las nociones mismas de dominado y de dominador. No solo el concepto de utopía que presentan los abordajes liberacionistas es puesto en cuestión, sino la utopía misma como productora de un saber teleológico que, por esa razón, apunta a una idealización de la sociedad desde una visión lineal de la historia, incluso en lo que respecta a los métodos utilizados por gran parte de los teóricos de la liberación, como lo ha sido la perspectiva materialista y dialéctica.

La segunda crítica, que, desde nuestro parecer, se desprende de la primera, en la que se defiende una positivización de la posmodernidad como lectura del presente, circunscribe la crisis de la razón latinoamericana (liberacionista, particularmente) a la muerte real, empírica, política y social de los grandes proyectos, relatos y utopías del socialismo. Es decir, una vez constatado el fracaso de ciertos proyectos históricopolíticos vinculados a una sociedad que pretendía superar el capitalismo moderno, también la noción utópica de los proyectos liberacionistas es condenada al fracaso o al romanticismo nostálgico, en el "mejor" de los casos.

Llama la atención la manera como Castro-Gómez (2011) interpreta las utopías latinoamericanas a partir de Lyotard, pues sus afirmaciones son sumamente similares a las de Popper y los teóricos neoliberales antiutopistas - lo que no haría fatua la crítica de los liberacionistas de la posmodernidad como Modernidad disfrazada al extremo-, pero también evidencian el desconocimiento de la noción de la crítica a la razón utópica aportada por Hinkelammert hace ya varias décadas: 
[...] uno de los reproches más populares que se han hecho a la posmodernidad de la filosofía latinoamericana: el haber proclamado el 'final de las utopías' [...] Partiendo de Wittgenstein [...] los juegos del lenguaje están estructurados de tal forma que a partir de ellos resulta imposible pensar una comunidad humana en donde no exista el conflicto y, por tanto, la injusticia [...] el resultado es el conflicto inevitable [...].

Según Lyotard, todo intento de 'reconciliar' las diferencias existentes entre los juegos del lenguaje y entre las formas de vida configuradas por ellos termina casi siempre en la dictadura y el terror [...].

¿Qué significa el final de este tipo de utopías totalizantes para la filosofía latinoamericana? ¿Será quizás la negación del 'discurso de futuro' como forma esencial de narrativa sobre las que se organiza gran parte de nuestro pensamiento, tal como lo teme Arturo Roig? [...] Seguramente que sí, cuando ese 'discurso de futuro' se identifica sin más con lo que se ha llamado la 'utopía americana' [...] que se caracteriza por su pretensión integral y totalizante [...] se trata de una retórica que ha servido para legitimar regimenes autoritarios y populistas de todos los colores en esta región [...] por eso al utopismo tendremos que oponer el perspectivismo.

[...] los posmodernos ya no criticamos el 'error' en nombre de la 'verdad', no queremos 'humanizarnos' ni buscar el origen de nuestra identidad cultural y tampoco nos conmueve la continuidad y la unidad, sino la multiplicidad y el acontecimiento. (Castro-Gómez, 2011, pp. 40-43)

Ahora bien, la manera como Hinkelammert piensa la utopía no se aproxima siquiera a la lectura que de esta ha hecho el filósofo colombiano. Por el contrario, el teórico de la liberación fue quizá el primero en referirse a esta desde una perspectiva crítica, develando que justamente el antiutopismo posmoderno tiene vieja data y su referente lo encuentra en los límites de la razón instrumental occidental, como en el surgimiento de una nueva etapa del capitalismo global. Hinkelammert ubica la problemática en torno de la utopía en tres tesis que dieron como resultado el antiutopismo del que Castro-Gómez hace referencia, basado en Lyotard. 
La primera tesis está vinculada a la transformación del capitalismo mundial, particularmente debido a la crisis del socialismo con la caída del Muro de Berlín en 1989. A la par con este acontecimiento, justo una semana después, los intelectuales jesuitas en San Salvador eran asesinados por las fuerzas del ejército, acontecimientos que van dando origen a la muerte o, mejor, asesinato de otro proyecto de sociedad pensado al margen de la racionalidad instrumental del capitalismo global.

El filósofo de la liberación menciona al respecto que esto se trató de una liquidación al clásico estilo del totalitarismo de los años treinta, por medio de la cual se extirpó —en términos reganianos- el “cáncer” de uno de los centros más importantes de la teología de la liberación (Hinkelammert, 1995, p. 26). Solo un mes después de estos episodios, Panamá es intervenida militarmente, lo que por demás contó con el amén de todas las sociedades occidentales, en las cuales circulan, casi neutralmente - sin oprimidos ni opresores-, las redes y relaciones del poder . Curiosamente, en este caso, son las fuerzas totalitarias las que aniquilan la utopía, que según el colombiano afirma, basado el Lyotard, “[...] siempre genera dictadura y terror” (Castro-Gómez, 2011, p. 40).

Respecto al capitalismo que surge después de estos episodios es claramente el del que Fukuyama puede ser identificado como uno de sus artífices con su texto The End of History? (1989). Es un capitalismo que se siente como el "vencedor" y lleva en su seno toda una doctrina del Departamento de Gobierno de EE. UU., que proclama, muy en el espíritu hegeliano, el fin de la historia, en la que “[... ya no habrá historia ni conflictos esenciales, en el cual el Primer Mundo habrá encontrado su paz, y en el cual el Tercer Mundo no cuenta" (Hinkelammert, 1995, p. 27). Este es el nuevo mundo, en el que existe un solo señor, una sola utopía posible, que es la antiutopía de otros mundos posibles.

La crisis del socialismo no le ha quitado al Tercer Mundo únicamente la posibilidad de buscar solidaridades en su conflicto con el Primer Mundo. Ya tampoco puede recurrir al socialismo en ese campo imaginario de la concepción de alternativas. Ya no puede usar al socialismo para demostrar que, en efecto, existe una alternativa, que se puede mejorar y que se tiene futuro; que comprueba que es posible tener otro futuro, tener en el futuro algo distinto de lo que es presente (Hinkelammert, 1995, p. 28).

El segundo y tercer elemento tienen que ver con las consecuencias de estos eventos que, según el economista, han generado una reestructuración no solo en la manera 
como las condiciones materiales de América Latina devienen, sino que en la comprensión del Tercer Mundo, que se “[...] transforma en un mundo en el cual vive una población que ha sido convertida en superflua" (Hinkelammert, 1995, p. 29). Es decir, lo que surge es una nueva manera de posicionar al sujeto latinoamericano, pues si bien el Tercer Mundo sigue siendo importante, con sus mares, naturaleza y demás, lo sobrante ahora es la mayor parte de la población, lo que no supone la retirada del Primer Mundo, sino el desarrollo, la invención de una nueva imagen de este y su población, vista ahora como sobrepoblación.

De allí nace una nueva manera de concebir los vínculos de solidaridad, pues dada la imposibilidad de buscar alternativas al capitalismo global, se declara ilusoria cualquier solidaridad humana. A propósito de esto, advierte: “[1]uego se persigue el intento mismo de ser solidario, como algo que es o ignorante o criminal. La solidaridad es perseguida como 'utopía' destructora” (Hinkelammert, 1995, p. 33).

Ahora bien, Hinkelammert no se lanza propiamente a dar una defensa a toda costa de la utopía socialista, sino que incluso considera que el colapso del socialismo es una evidencia más de la crisis del capitalismo, en el sentido en que el socialismo soviético fue un intento al interior de la racionalidad occidental por solucionar la crisis del capitalismo, pero aún al interior de la sociedad occidental: “[e]l colapso del socialismo soviético revela el hecho de que la crisis del capitalismo no es apenas del capitalismo, sino de la sociedad occidental" (Hinkelammert, 1995, p. 140).

\section{Utopía como ausencia de totalidad}

El aparente fracaso del proyecto socialista de sociedad y, en consecuencia, la imlementación del sistema capitalista mundial y, particularmente, el lugar que ocupa en este la población sobrante del denominado Tercer Mundo hacen que vuelva al escenario algo que Hinkelammert ha identificado en su texto Crítica a la razón utópica (1984) y que, según el autor, es propio de la racionalidad burguesa, a saber, el carácter aparentemente antiutópico de este nuevo "desorden" mundial. Este antiutopismo disfrazado no nace propiamente con el neoliberalismo actual, sino que es reciclado del neoconservadurismo, solo que ahora el antiutopismo es también antisocialismo:

Antiutopía significa aquí, simplemente, antisocialismo, produciéndose un pensamiento de elaboración antiutópica que vuelve a ser una réplica más 
extrema del mito de la mano invisible, que siempre ha sido una expresión de esta ingenuidad utópica. Su lema es: destruir la utopía para que no exista ninguna otra. Especialmente Hayek y Popper son los portadores de este extremismo utopista camuflado, de la antiutopía como utopía verdadera. (Hinkelammert, 1990, p. 13)

En contraste con estas posturas, Hinkelammert propone no un antiutopismo, sino la crítica misma a la razón utópica, pues lo que observa en estos teóricos del antiutopismo es el hecho de que "[...] la ingenuidad utópica con su potencialidad destructora no puede volver sino en nombre de la antiutopía, en nombre de la utopía de una sociedad sin utopías" (1990, p. 14). De allí que valiéndose de ciertos aportes de Kant, particularmente de sus críticas trascendentales a la razón, el intelectual considera que una crítica a la razón utópica consiste justamente en la transformación de los contenidos utópicos modernos en conceptos y reflexiones trascendentales: “[c] omo las críticas kantianas a la razón son críticas trascendentales de ella, yo intento demostrar que también la crítica a la razón utópica no puede ser sino una crítica trascendental" (1990, p. 16).

Es quizá este punto de partida kantiano del utopismo liberacionista el que más puede incomodar a los teóricos posmodernos, pues el concepto de crítica trascendental está relacionado con la noción de voluntad pura - lo que debe ser-, sin embargo, lo que resalta Hinkelammert no es propiamente el dualismo que subyace en el pensamiento del escritor de Crítica a la razón pura, sino el hecho de que aquella voluntad pura no tiene consideraciones de factibilidad, pues "[...] siempre aspira a lo imposible en cuanto aspira a lo mejor" (Casos, 2008, p. 21). Dicha aspiración se da por medio de la imaginación, pero también a través de la conceptualización de lo imposible, gracias a lo cual, se descubre, emerge lo posible: "[s] i no nos atrevemos a concebir lo imposible, jamás podemos descubrir lo que es posible. Lo posible resulta pues del sometimiento de lo imposible al criterio de factibilidad" (Casos, 2008, p. 21).

Pues bien, una cosa es captar lo posible por medio de la conceptualización de lo imposible y otra es pretender la persecución y realización de ese posible por la ilusión de conseguir aquel imposible:

Por lo tanto, la ilusión de poder realizar sociedades perfectas es una "ilusión trascendental" que distorsiona el realismo político. Tal ilusión trascendental 
se supera únicamente por una crítica que revele el carácter trascendental de los conceptos de perfección, pero sin pretender renunciar a ellos (Casos, 2008, p.21)

Dado que Hinkelammert comprende la política como el arte de lo posible (1990), lo que en sí mismo es una crítica al utopismo, aquello que es no posible no es lo dado, sino aquello por descubrir. Sin embargo, lo que sí puede saberse, lo descubierto, pasa necesariamente por la conceptualización de lo imposible frente a lo cual se abre y experimenta lo que es posible:

En efecto, estas imposibilidades también tienen su historia, porque acompañan como conceptualizaciones imposibles al descubrimiento de las posibilidades humanas. Aceptar esta historia, tanto de las posibilidades como de las imposibilidades humanas, es parte del realismo político. (Casos, 2008, p. 219)

Esta es la razón de que la crítica a la razón utópica de Hinkelammert no presente un rechazo de lo utópico, pues, por demás, esto no es posible, sino su conceptualización trascendental en el sentido de que lo que busca es evidenciar los peligros totalitarios de la utopía cuando esconde la pretensión de una factibilidad cerrada, lo que en palabras del economista es una "ilusión trascendental".

En términos muy generales y siguiendo la lectura que Casos (2008) y Fernández (2004) hacen del economista, podríamos sintetizar la noción de utopía de Hinkelammert bajo tres elementos. El primero de estos ubica la utopía no propiamente como ideología, sino como condición humana; es por esto que el autor afirma que "[...] lo que hay que discutir, en cambio, es la necesidad de una relación realista con la utopía y sus horizontes. La negación de la utopía jamás es realista” (1995, p. 207). Esto nos conduce a una segunda afirmación, según la cual “[...] la negación de la utopía es una rebelión en contra de la condición humana igual como lo es la pretensión de realizarla”. Este hecho no contradice los abordajes de las ciencias empíricas que se presentan a sí mismas como la superación de las utopías; por el contrario, devela en estas su propio horizonte utópico negado. Ahora bien, este reconocimiento de los límites de la utopía en el marco de la condición humana conlleva a que esta anticipación utópica se devele en el interior mismo de la condición humana, es decir: 
Tiene que hacer presente en la vida actual una esperanza utópica, cuya realización es excluida por la propia condición humana. En el interior de esta condición humana tiene que vislumbrar la esperanza de lo imposible, encarnándola en un mundo que sigue estando condicionado por la muerte. (Casos, 2008, p. 24)

Por su parte la filósofa Estela Fernández (2004) en su minucioso estudio del pensamiento de Hinkelammert observa que la racionalidad occidental cambió la idea de mundos trascendentes — cielo, el Reino de Dios-, por mundos trascendentales, por medio de idealizaciones construidas por abstracción que se "[...] proyectan al futuro como mecanismos de funcionamiento perfecto”. Esta abstracción, según Fernández, se da ante una realidad que no se conforma, razón por lo cual se erige un mundo mejor y cuya función es la orientación de la praxis, pero que, en sentido fáctico, no es realizable, justamente por ser resultado de una idealización, construida por vía de abstracción (Fernández, 2004, p. 733).

El problema es que la razón moderna olvida el carácter trascendental de sus utopías, lo que hace que se las proyecte como si fuesen fácticamente realizables en el futuro, a manera de la curva asintótica en las matemáticas.

Para Hinkelammert los conceptos abstractos de perfección, las ideas utópicas, son reguladoras de la práctica en cuanto totalidad ausente y no presentificable en términos reales, mientras que para la racionalidad moderna occidental estas abstracciones son vistas como ámbito de plenitud, como aproximación asintótica. En términos del intelectual, estas son totalidad presente. A lo que Fernández comenta que:

Precisamente la construcción de las utopías proyectadas a futuro y pensadas como modelos de perfección efectivamente alcanzables en el tiempo a partir de una aproximación asintótica es una de las facetas de la dominación desplegada por el sujeto moderno sobre la naturaleza y sobre el otro social [...] La única forma de frenar este espiral de irracionalidad que nos lleva al suicidio colectivo es pensar la 'totalidad' de otros modo, no como una presencia que está a la mano, a la vuelta del camino histórico, sino como 'ausencia': inicio de la paradójica condición de un ser que aspira a la infinitud y a la transparencia, y tiene que realizarse en el marco de la finitud y la opacidad. (2004, p. 734) 
En este sentido, en la idea de utopía propuesta por Hinkelammert aún subyace un ideal de totalidad, pero este se da como la proyección de un ideal regulativo imposible, que empero permite dimensionar lo posible.

Esta totalidad dada en la utopía hinkelarmmiana es concebida como un horizonte siempre ausente que exige una aproximación práctica y sujeta a la reformulación constante de cara al devenir histórico y material de los sujetos. Esto está en oposición a la totalización del sistema que basa su legitimación en la muerte y clausura de todo horizonte que ose trascenderle. Esta totalidad, en la obra de Hinkelammert, es ausencia presente que se opone la utopía del statu quo que es totalidad presente, funcional a la sociedad real y que no devela ninguna ausencia de totalidad y, por ende, es una utopía acrítica e irracional.

Solo si la utopía se piensa como idea de una totalidad que falta, se convierte en un instrumento que permite reclamar la plenitud humana negada en la totalización real. En tal sentido, no se convierte a la ausencia de esa plenitud deseada en la meta futura de una aproximación asintótica, en un programa que se aspira a realizar o en una cosa que se quiere alcanzar — según el modelo medio-fin que constituye la modernidad como tal-, sino como ausencia trascendental que interpela y juzga (Fernández, 2004, pp. 736-737).

\section{Las utopías de la totalidad presente y muerte de las utopías otras}

La crítica a las utopías de la totalidad, presente en la obra de Hinkelammert, tiene su origen en sus análisis del neoliberalismo del siglo XX, que, según el autor, comparte una continuidad con el pensamiento conservador al partir ambas de un concepto de realidad precaria que la restringe a los elementos institucionales. Por esta razón, lo que se identifica como realidad precaria en el neoliberalismo es la institución burguesa del mercado, como concepto límite central. De la misma manera que, para Berger, en su pensamiento conservador, el transgredir las instituciones era una trasgresión en contra de la sociedad misma, para el neoliberalismo es el mercado la realidad precaria y, por lo tanto, el ponerla es una amenaza, resultado de la "estupidez y el egoísmo".

Para la construcción de esto aparecen dos conceptos límites, como el caos y el mercado - o la competencia perfecta- - Si bien ninguno de los dos es un concepto 
empírico, ambos trascienden la realidad empírica del mercado y, por lo tanto, se constituyen como conceptos trascendentales desde los cuales la realidad empírica es interpretada. Al respecto refiriéndose a uno de los teóricos neoliberales, Friedrich Hayek, afirma que:

[...] partió del mercado empírico, pasó a construir de forma idealizada un concepto límite del mercado llamado competencia perfecta (equilibrio), constató que no es calculable y concluye que podemos esperar que el mercado empírico producirá una aproximación a este equilibrio idealizado. Eso es lo que desde la mano invisible de Adam Smith sostiene la teoría económica burguesa en contra de todas las evidencias empíricas del caso. Se idealiza un fenómeno empírico y se concluye que este se acerca a esa su idealización. (Hinkelammert, 1990, pp. 58-60)

La utopía neoliberal confunde sin más conceptos empíricos con conceptos trascendentales al partir de la idea de la competencia perfecta que, en sí misma, encierra su propia contradicción, pues la competencia requiere el desequilibrio y, por lo tanto, no puede llevar al equilibrio. A este concepto límite positivo de equilibrio, vía competencia perfecta, le corresponde un concepto límite negativo del caos y la destructibilidad. Por esta razón, cualquier alternativa al sistema de mercado es vista como irracional y peligrosa. Dado que las alternativas socialistas pensaron una sociedad al margen de las relaciones mercantiles y bajo una idea de la planificación perfecta —central—, al intentar una sociedad así, se intenta lo imposible y al hacerlo, es decir, al “[...] buscar el cielo en la tierra se consigue el infierno”. En palabras de Karl Popper:

Como otros antes que yo, llegué al resultado de que la idea de una planificación social utópica es un fuego fatuo de grandes dimensiones, que nos atrae al pantano. La hybris que nos mueve a intentar realizar el cielo en la tierra, nos seduce a transformar la tierra en un infierno; un infierno como solamente lo pueden realizar unos hombres contra otros. (citado por Hinkelammert, 1990, p. 66)

Llama la atención la semejanza entre las palabras de Popper y las de Lyotard, mencionadas por el colombiano Santiago Castro-Gómez, al abordar la imposibilidad de la utopía liberacionista (2011, p. 42). Esto pone de manifiesto la continuidad de la racionalidad antiutópica de las filosofías posmodernas con la Modernidad al extremo. 
Esta transformación del mercado en Hayek como totalidad presente le lleva a mistificarlo, es decir, este se transforma en una institución milagrosa, fuera de la cual no es posible otro mundo. Así, en contraste con la imposibilidad de la planificación perfecta y central del socialismo, el mercado se presenta como milagro, el cual, según Hayek, consiste en que en el caso de escasez de una materia prima:

[...] decenas de miles de hombres pueden ser llevados a ahorrar este material y sus productos, cuya identidad se podría establecer solamente en investigaciones en largos meses, y sin que se den órdenes algunas y sin más que un puñado de hombres conozcan las causas [...] Eso es suficientemente milagroso. (Hinkelammert, 1990, p. 76)

Como resultado de lo anterior aparece lo que Hinkelammert ha denominado la idolatría del mercado, pues este ocupa el lugar de la razón y ante este el hombre solo pude guardar silencio, callar y someterse. De ahí se desprende la primera virtud ética del neoliberalismo, la humildad, que supone el sacrificio mismo de la vida en nombre de la utopía del mercado perfecto.

\section{Alternativas y aportes a la memoria}

Según Hinkelammert, cuando hablamos hoy de muerte de las utopías, se piensa en esta de la forma en que Lasky lo propuso, poco objetivamente y con una condena a priori de esta, "[...] la ausencia de la utopía es tanto la repugnancia de las condiciones presentes como las seducciones de un mundo mejor" (citado por Hinkelammert, 1995, p. 202). Sin embargo, si quitamos la "repugnancia” y "seducción” que se tiene a priori acerca de esa idea, la utopía alcanza su contenido objetivo que versaría acerca de "[...] la crítica de las condiciones presentes y la esperanza de un mundo mejor".

La utopía en la que piensa Lasky corresponde ciertamente a la del comunismo soviético, de la sociedad nietzscheana sin esperanzas, de la utopía neoliberal del mercado total; todas estas prometen un mundo mejor, pero al margen de toda factibilidad humana, más allá de la condición humana y ninguna permite la más mínima crítica del presente; "por el contrario, prometen la realización de otro mundo en nombre de la celebración de las condiciones presentes". En ese sentido pleno, la relación con la realidad se da al “[...] crear un mundo cuya conservación vale la pena”, pero esto solo para unos pocos (Hinkelammert, 1995, p. 202). 
El concepto de utopía de Lasky no le permite captar el momento en que la utopía es presentada como mistificación y sacralización del presente, es decir, cuando esta deja de ser una crítica de las condiciones presentes y pasa a legitimarlas, cuando deja de ser crítica y se convierte en conservadora.

La utopía crítica busca alternativas; la negación de la crítica, en cambio, se deriva de la tesis de que la sociedad afirmada es la única alternativa, para lo cual no existe ninguna otra. La crítica es transformada en algo absurdo, en un asunto de tontos o traicioneros (Hinkelammert, 1995, p. 203).

En este sentido, la utopía crítica crea un mundo cuya conservación es imposible, pues la crítica siempre se dirige hacia un futuro abierto, pero signado por la transformación del presente; esta búsqueda de futuro abierto no es una curva asintótica infinita — como puede suceder en algunas propuestas de la liberación- “[...] sino un constante rehacerse de la sociedad frente a sus problemas más candentes en cada momento" (Hinkelammert, 1995, p. 206).

Esta utopía es una que emerge a partir de la afirmación de la vida frente a una lógica que legitima el sacrificio de muchos al mercado como totalidad presente. Ahora bien, la afirmación de la vida no puede ser meramente un cliché humanista o una declaración romántica, sino que hace imperativa la reformulación de la civilización occidental. Por esto, tiene que reformularse a partir de los excluidos y empobrecidos. Según Hinkelammert, este es el único imperativo categórico que puede parar el holocausto que en nombre de las utopías de la totalidad presente se dan en por medio del sistema económico mundial.

La afirmación de la vida de los excluidos y empobrecidos, si bien es una afirmación de valor, es una sin la cual no se puede vivir, pues parte de exigencias que se derivan del hecho mismo de que la humanidad quiere garantizar su propia sobrevivencia. En palabras del economista:

Aparecen a partir del propio análisis científico, sin que haya ningún Sinaí externo desde el que sean pronunciados. Al hacerse la tierra cada vez más redonda e interdependiente, el asesinato resulta ser un suicidio. Si no queremos ser suicidas tenemos que dejar de ser asesinos. No obstante, no podemos dejar de serlo sin afirmar precisamente toda vida a partir de la afirmación de la vida de los excluidos. (Hinkelammert, 1995, p. 150) 
Es, por esta razón, que en la teología y filosofía de la liberación, aunque de maneras diferentes, el excluido, el pobre, la naturaleza devastada son el loci donde se revela Dios. Esto constituye no propiamente una ética, sino la raíz, su condición la ética y no un deplorable juicio de valor, como lo postulan las teorías burguesas de la ciencia. A propósito de esta, afirma Hinkelammert que “[...] opción por los pobres [...] implica una postura moral: el victimario es culpable".

Ante una sociedad en la que cualquier alternativa es imposible e irracional es necesario postular un horizonte en el que la política se conciba como arte de lo posible que abre el horizonte para hacer posible lo imposible y para realizarlo. Para que la política sea realista, deberá superar la Realpolitik y permitir la transformación de la realidad, pues toda política está enfrentada a la problemática de lo imposible, desde lo cual se deduce lo posible.

Para un verdadero realismo político, la utopía se convierte entonces en la apertura de futuro y, en ese sentido, en una fuente de inspiración y referencia de juicio, sabiendo que su realización definitiva o calculante nunca es una posibilidad, sino más una idea regulativa: “[s]ólo así se puede asegurar que la utopía no vuelva a desembocar en una 'dialéctica maldita” y que sea fuente de vida y esperanza.

Es en este horizonte de la utopía crítica en el que la memoria recobra sentido, pues la utopía se constituye como el para qué y no meramente en la institucionalización de la historia de quienes no han tenido historia. 


\section{Referencias}

Casos, A. (2008). Fetichismo, crítica de las utopías y teología de la liberación en Franz Hinkelammert. Revista Discusiones Filosóficas desde Acá, (6). Recuperado de: http://www.ideaz-institute.com/sp/CUADERNO6/C62.pdf

Castro-Gómez, S. (2011). Crítica a la razón latinoamericana. Bogotá: Javeriana.

Fernández, E. (2004). Crítica y utopía en la filosofía de Franz Hinkelammert. Revista Realidad, (102)

Foucault, M. (1992). Nietzsche, la genealogía, la historia. En Microfísica del poder (J. Varela y F. Álvarez Uría, Trads.). México: La Piqueta.

Fukuyama, F. (1989). ¿El final de la historia? The National Interest, (número).

Gallardo, H. (1990). Francis Fukuyama: el final de la historia y el Tercer Mundo. Revista Pasos, (28).

Gutiérrez, G. (1975). Teología de la liberación: perspectivas. Salamanca: Sígueme.

Hinkelammert, F. (1995). Cultura de la esperanza y sociedad sin exclusión. San José: DEI.

Hinkelammert, F. (1984/1990). Crítica a la razón utópica. San José: DEI.

Hinkelammert, F. (2012). Lo Indispensable es inútil: hacia una espiritualidad de la liberación. San José: Arlekín.

Horkheimer, M. (1976). La añoranza de lo completamente otro. En H. Marcase y K. Popper (Eds.), A la búsqueda del sentido. Salamanca: Sígueme.

Leventhal, M. (2012). El peso de la historia; frases célebres comentadas por grandes historiadores. Barcelona: Crítica.

Mo Sung, J. (2005). Sujeto y sociedades complejas: para repensar los horizontes utópicos. Son José: DEI.

Orwell, G. (2009). 1984: Ancora y Delfín. Barcelona: Destino.

Pedreño, J. (2004). ¿Qué es la memoria histórica? Revista Pueblos, (12), 10-12. Recuperado de http://www.rebelion.org/noticias/2004/7/2032.pdf

Trenchard, E, y Ruiz, A (1994). El libro del Éxodo. Madrid: Portavoz. 